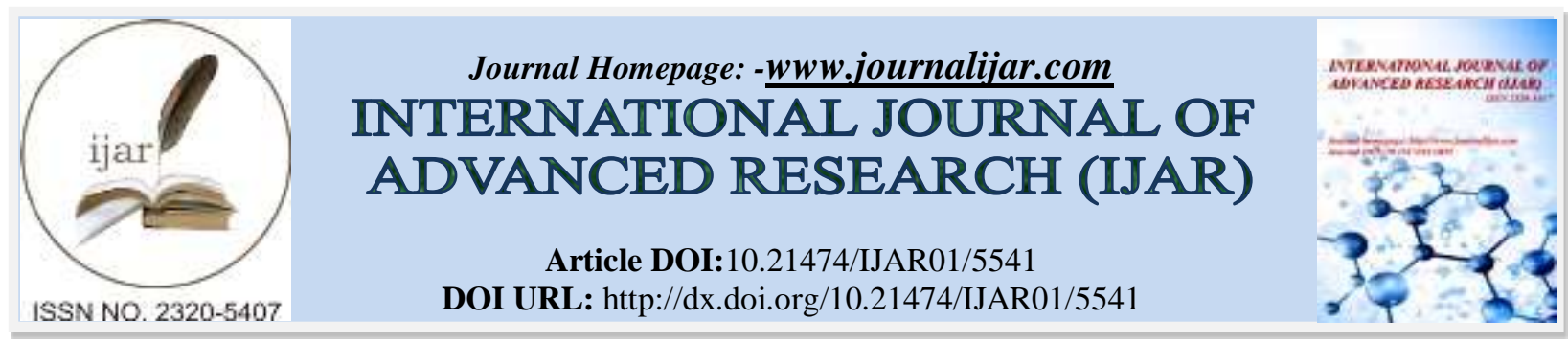

RESEARCH ARTICLE

\title{
ISOLATION, PURIFICATION AND APPLICATION OF SECONDARY METABOLITES FROM SEAWEED HYPNEA CERVICORNIS
}

Leela.K and *Anchana Devi.C.

PG \& Research Department of Biotechnology, Women's Christian college, College road, Chennai - 600006, Tamilnadu, India

\section{Manuscript Info}

Manuscript History

Received: 05 August 2017

Final Accepted: 07 September 2017

Published: October 2017

Key words:-

Hypnea cervicornis, Secondary

metabolites, Column chromatography,

Gas chromatography-Mass spectrometry.

\begin{abstract}
Seaweeds are marine non-flowering plants commonly referred to as macroalgae. They are one of the commercially important sources and are found to possess the ability to synthesize numerous secondary metabolites such as phenols, terpenes, steroids which have wide applications in the field of medicine. They are also widely utilized in the production of polysaccharides such as carrageenan, fucoidan etc., and have both therapeutic and industrial applications. The Present study was aimed to isolate, purify and determine the applications of secondary metabolites from Seaweed Hypnea cervicornis. In this study two important secondary metabolites such as glycosides and alkaloids were targeted. The presence of these compounds were detected by means of performing thin layer chromatography using specific solvent systems and purified by column chromatography. The purified fractions were then identified by means of Gas chromatography -Mass spectrometry (GC-MS). The compounds were then subjected to application oriented studies such as antimicrobial activity, antioxidant activity and antidiabetic activity. Not much work have been carried out on the isolation of a specific glycoside and alkaloid compound from Seaweed Hypnea cervicornis so this study was an attempt to explore the applications of these individual compounds which could prove beneficial to the mankind for different purposes.
\end{abstract}

Copy Right, IJAR, 2017,. All rights reserved.

\section{Introduction:-}

Marine organisms are considered to be potentially beneficial sources with enormous secondary metabolites for their use as pharmaceutical agents. The Production and development of new compounds from these marine sources are found to be rapidly increasing and among these sources marine algae still remains under exploited condition (Blunt J.W et al., 2012).The term marine alga refers to macro algae or seaweeds. Seaweeds are one of the commercially important sources which belong to the group of non-flowering plants and are found to possess the ability to synthesize numerous secondary metabolites such as phenols, terpenes, steroids which have wide applications in the field of medicine. Seaweeds contain unique phytochemicals, vitamins and minerals which play an important role as antioxidant agent. They are widely utilized in food, cosmetics and nutraceuticals due to their economical and dietary resources. They are also found to possess proteins, carbohydrates, vitamins, minerals which are thereby utilized in animal nutrition (Sara Marsham et al., 2007). Since it is a renewable resource and easily available seaweeds are widely used as food, fertilizer and fodder from the ancient times. 
Hypnea cervicornis is a common epiphyte that belongs to the family Hypneaceae also referred to as hooked red weed and is found to be widely distributed in Atlantic, Caribbean, Indian and Pacific oceans. It measures about 3-30 $\mathrm{cm}$ long and occurs in tangled and bushy clumps. It is generally yellowish green but appear to be deep red when shaded and it mostly remains either attached to rock or on other algae mostly species of Sargassum (Littler DS et al.,1989). It is the economically important seaweed which is used in the production of polysaccharides such as carrageenan which is used as a binding and smoothing agent in many commercial products such as toothpaste, ice cream, pet foods, etc. and has wide applications in different industries especially in the food industry.

Secondary metabolites are generally organic compounds synthesized by different sources such as plants, algae, bacteria, fungi etc. They are biosynthetically derived from primary metabolites. These compounds are restricted to a set of species within a phylogenetic group and are not directly involved in the growth, development and reproduction of an organism. Four major classes of secondary compounds are phenolics, glycosides, alkaloids and terpenoids. These secondary compounds play an important role in different industries and are mainly used as medicines, flavourings and as recreational drugs. In the current study two different secondary metabolites have been targeted and isolated they are Glycosides and Alkaloids.

Glycoside is a naturally occurring compound in which a carbohydrate portion consisting of one or more sugars is combined with a hydroxy compound. The hydroxy compound is usually a non-sugar entity such as derivative of phenol or alcohol. They play a wide role in therapeutic applications. Glycoside is generally classified into different types based on chemical nature of Non-sugar moiety, the nature of sugar moiety, linkage between glycon and aglycone portion and its therapeutic nature (Fig 1).

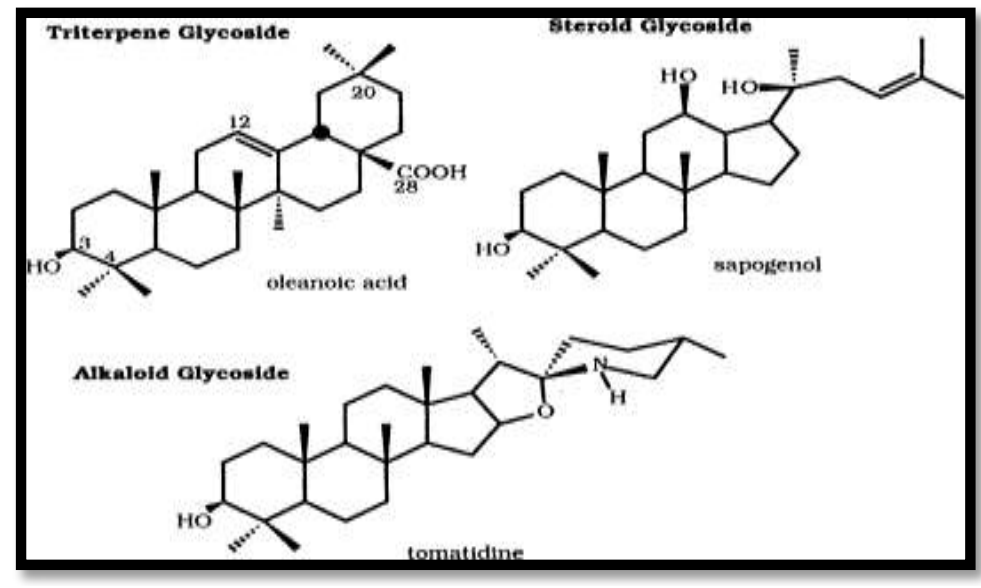

Figure 1:-Classification of Glycosides

Alkaloids are compounds that possess a ring structure and a nitrogen residue. They are mainly derived from aminoacids such as tyrosine, tryptophan, ornithine, arginine and lysine. Among the different groups of alkaloid indole alkaloid is the largest group derived from tryptophan. There are 3 types of alkaloids namely true alkaloids, Proto alkaloids and Pseudo alkaloids. They play an important role in pharmaceutical industry due to their analgesic, narcotic, anti- malarial, anti-pyretic, anti-cancer and anti-inflammatory activities (Fig 2). 


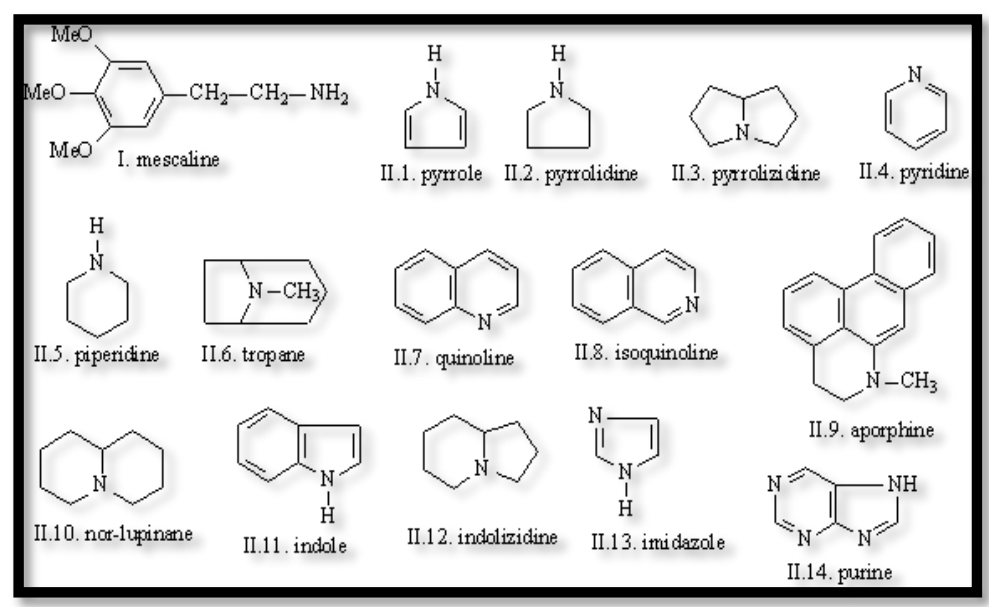

Figure 2:- Classification of Alkaloids

Thus in the present study the antimicrobial, antioxidant and antidiabetic applications of Glycoside and Alkaloid compounds isolated and purified from the Seaweed Hypnea cervicornis were determined.

\section{Materials and Methods:- Sample Preparation:-}

The Seaweed Hypnea cervicornis samples were collected manually from Pazhaverkadu brackish water area at Thiruvallur district, Chennai and were identified based on their morphological characteristics (Abbott I.A., 1996). The samples were cleaned, washed under tap water and distilled water to remove the dirt and were dried for about 3 days and powdered. The powdered samples were stored in clean bottles for further analysis.

Extraction of Samples: (Daisy A et al., 2016)

The crude extract from the Seaweed samples were obtained by means of cold extraction method using methanol as solvent. About $50 \mathrm{~g}$ of the powdered seaweed sample was added to $500 \mathrm{ml}$ of methanol separately in a conical flask, covered with aluminium foil and kept on a rotary shaker for 3 days at room temperature. The solution was filtered with the help of Whatman No.1 filter paper and the filtrate obtained was evaporated. The dried extracts were then stored for further analysis. The yield of respective crude extract was calculated as:

$$
\text { Percentage yield }(\%)=(\text { dry weight of extract } / \text { dry weight of samples }) \times 100 \text {. }
$$

\section{Isolation and Purification of Secondary metabolites:-}

Thin Layer Chromatography: (Viseshni R et al., 2017)

Thin-layer chromatography (TLC) is a chromatographic technique used for separating different components from a mixture. It is generally carried out on a thin sheet of plastic, glass or an aluminium foil which is coated with an absorbent material. The layer of adsorbent material is called as stationary phase. The sample is spotted on the plate and the solvent or mixture of solvents acts as a mobile phase via capillary action. TLC plate is cut and using a pencil line is drawn about $1 \mathrm{~cm}$ from one end of the edge. Markings are made and the samples were spotted on to the plate using a capillary tube for each spot. The spots should be air dried. The TLC chamber consists of a glass jar with a lid and the solvent mixture is added to chamber. The Mobile phase used for isolation of glycosides are (Toluene: methanol: glacial acetic acid: water $=7: 4: 3: 1$ ) and for alkaloids are (Butanol: acetic acid: water $=4: 1: 3$ ). The TLC plates were placed carefully in the TLC chamber. The solvent mixture should be below the spot on the plate and the chamber is kept closed. As the solvent moves up due to capillary movement, the compounds present in the extract are seperated. The TLC plates are then removed from the chamber once the solvent reaches an approximate level in the plate and is kept for drying. The plates are dried and spots can be visualized by using a suitable spraying reagent. For glycosides Iodine chamber is used while for alkaloids Dragendroff's reagent is used for identification (Kumar et al., 2007) (Gurpreet kaur et al., 2014). The formation of brown band indicates the presence of glycosides and the formation of reddish orange band indicates the presence of alkaloids. The $\mathrm{R}_{\mathrm{f}}$ value is calculated using the formula:

$$
\mathrm{R}_{\mathrm{f}}=\text { Distance travelled by the solute / Distance travelled by the solvent }
$$


Column chromatography: (K.Nanthini Devi et al., 2012)

Silica gel (100 - 200 mesh) was chosen as the stationary phase. The column was packed with silica gel using methanol once packed the crude residue from methanol extract was transferred onto the bed of silica gel. The column was run by using mobile phase (Toluene: methanol: glacial acetic acid: water in the ratio of 35:20:15:10) for glycosides and (Butanol: acetic acid: water in the ratio of 40:10:30) for alkaloids. The fractions were collected at an interval of $5 \mathrm{ml}$ each and are monitored by means of thin layer chromatography. The fractions obtained were stored and utilized for the identification of individual compounds present in the sample by means of Gas chromatography - Mass spectrometry (GC-MS).

Confirmatory test: (Sibi G et al., 2013)

1. Glycosides: Keller - Killani Test: To $1 \mathrm{ml}$ of sample add $1 \mathrm{ml}$ of glacial acetic acid and $1 \mathrm{ml}$ of conc.sulphuric acid. Appearance of reddish brown colour at the junction of 2 layers indicates the presence of glycosides.

2. Alkaloids: Dragendroff's test: To $2 \mathrm{ml}$ of sample 2-3 drops of Dragendroff's reagent is added. Appearance of orange red coloured complex indicates the presence of alkaloids

\section{Identification of Secondary metabolites:-}

Gas chromatography - Mass spectrometry (GC-MS): (Rajasekar Thirunavukkarasu et al., 2014)

It is an analytical method used for identifying different substances within a test sample. It also helps in identifying trace elements in a sample. The Clarus $680 \mathrm{GC}$ was used for the analysis and a fused silica column was employed and packed with Elite-5MS (5\% biphenyl 95\% dimethylpolysiloxane, $30 \mathrm{~m} \times 0.25 \mathrm{~mm} \mathrm{ID} \times 250 \mu \mathrm{m} \mathrm{df}$ ) and the components were separated using Helium as carrier gas at a constant flow of $1 \mathrm{ml} / \mathrm{min}$. The injector temperature was set at $260^{\circ} \mathrm{C}$ during the chromatographic run. The $1 \mu \mathrm{L}$ of extract sample was injected into the instrument and the oven temperature was as maintained as follows: $60^{\circ} \mathrm{C}(2 \mathrm{~min})$; followed by $300{ }^{\circ} \mathrm{C}$ at the rate of $10{ }^{\circ} \mathrm{C}$ min- -1 ; and $300{ }^{\circ} \mathrm{C}$, where it was held for $6 \mathrm{~min}$. The mass detector conditions were: transfer line temperature $240{ }^{\circ} \mathrm{C}$; ion source temperature $240{ }^{\circ} \mathrm{C}$; and ionization mode electron impact at $70 \mathrm{eV}$, a scan time $0.2 \mathrm{sec}$ and scan interval of $0.1 \mathrm{sec}$. The fragments were obtained from 40 to $600 \mathrm{Da}$. The spectrums of the components were compared with the database of spectrum of known components stored in the GC-MS NIST (2008) library.

\section{Applications:-}

\section{Antimicrobial activity:}

The antibacterial activity of Purified glycoside and Purified alkaloid fractions of Seaweed (Hypnea cervicornis) were screened against both Gram positive and Gram negative bacteria such as Staphylococcus aureus, Streptococcus spp, Escherichia coli, Klebsiella pneumoniae, Salmonella spp and Pseudomonas aeruginosa while the antifungal activity was carried out against Aspergillus spp and Candida albicans.

\section{Agar well diffusion method: (B.Hebsibah Elsie et al., 2010)}

The stock cultures were maintained at $4^{\circ} \mathrm{C}$ on the nutrient agar slant slopes. Nutrient broth was prepared for about $50 \mathrm{ml}$ and a loop-full of stock cultures were transferred to $50 \mathrm{ml}$ of nutrient broth and were incubated at $37^{\circ} \mathrm{C}$ for 24 hours. The strains were inoculated in nutrient broth for 24 hours. Potato dextrose broth was prepared for the growth of fungal strains and incubated for 48 hours. About $250 \mathrm{ml}$ of Muller Hinton agar medium (MHA) was prepared for antibacterial activity while Potato Dextrose agar medium (PDA) was prepared for antifungal activity and poured into the petriplates and was allowed to solidify. Once solidified the bacterial cultures and the fungal cultures were swabbed onto the agar medium using a sterile cotton swab. The wells were punctured on the inoculum spreaded plates using a sterile cork borer. Different concentrations of samples $(20,40,60,80 \mathrm{mg} / \mathrm{ml})$ were dispensed into each well using a micropipette. The bacterial petriplates were then incubated at $37^{\circ} \mathrm{C}$ for 24 hours and the fungal petriplates were incubated at $37^{\circ} \mathrm{C}$ for 2 or 3 days and observed for the zone of inhibition. The diameter of the zone of inhibition was measured in $\mathrm{mm}$.

\section{Antioxidant activity:-}

The antioxidant potential of Purified glycoside and Purified alkaloid fractions of Seaweed (Hypnea cervicornis) were determined by 3 methods: Total antioxidant capacity (TAC) assay, Hydrogen Peroxide $\left(\mathrm{H}_{2} \mathrm{O}_{2}\right)$ scavenging assay and reducing power assay

Total antioxidant capacity assay::About $1 \mathrm{ml}$ of the test sample is added to $3 \mathrm{ml}$ of freshly prepared phosphomolybdenum reagent and was incubated for about 90 minutes in water bath at $95^{\circ} \mathrm{c}$.It was then cooled to 
room temperature and absorbance was measured at $695 \mathrm{~nm}$ in a spectrophotometer. $1 \mathrm{ml}$ methanol without extract was used as blank. Ascorbic acid was used as the standard (Prieto et al., 1999). The Total antioxidant capacity (TAC) can be calculated using the formula:

$$
\text { Total antioxidant capacity }(\text { TAC })=(\text { A of Control }- \text { A of test }) / A \text { of Control } \times 100
$$

Hydrogen peroxide scavenging assay: Solution of Hydrogen peroxide (40mM) was prepared in phosphate buffer (pH 7.4). $1 \mathrm{ml}$ of the test sample was added to $3 \mathrm{ml}$ of Hydrogen peroxide solution and was incubated at room temperature for 10 minutes and the absorbance was determined at $230 \mathrm{~nm}$ in a spectrophotometer. Ascorbic acid was used as the standard. Phosphate buffer without hydrogen peroxide served as blank (Ruch et al., 1989).It can be calculated using the formula:

$$
\% \text { scavenged }\left(\mathrm{H}_{2} \mathrm{O}_{2}\right)=(\mathrm{A} \text { of Control }-\mathrm{A} \text { of test } / \mathrm{A} \text { of Control }) \times 100
$$

Reducing power assay: In this method $2.5 \mathrm{ml}$ of sample was mixed with $2.5 \mathrm{ml}$ of phosphate buffer (0.2M, pH 6.6) and $2.5 \mathrm{ml}$ of $1 \%$ Potassium ferricyanide $(10 \mathrm{mg} / \mathrm{ml})$. The mixture was incubated at $50^{\circ} \mathrm{c}$ for 20 minutes then rapidly cooled and mixed with $2.5 \mathrm{ml}$ of $10 \%$ trichloroacetic acid and centrifuged at $6500 \mathrm{rpm}$ for 10 minutes. About $2.5 \mathrm{ml}$ of supernatant was diluted with $2.5 \mathrm{ml}$ of distilled water and then $0.5 \mathrm{ml}$ of $0.1 \%$ ferric chloride was added and allowed to stand for 10 minutes. The absorbance was read spectrophotometrically at 700nm (Ferreira et al., 2007).

Antidiabetic activity: (Murugesan S et al., 2016)

The antidiabetic activity of Purified glycoside and Purified alkaloid fractions of Seaweed (Hypnea cervicornis) were determined by means of alpha amylase inhibition assay.

Alpha amylase inhibition assay: About $1 \mathrm{ml}$ of the sample was added to $1 \mathrm{ml}$ starch solution and was incubated for 10 minutes at room temperature. $0.5 \mathrm{ml}$ of the prepared enzyme solution was added to the mixture and was incubated at $25^{\circ} \mathrm{c}$ for about 10 minutes. The reaction was then terminated by the addition of $1 \mathrm{ml}$ of colorimetric reagent and was kept in water bath for 5 minutes and cooled to room temperature. This was further diluted by adding $10 \mathrm{ml}$ of distilled water and the absorbance of the mixture was measured at 540nm in colorimeter. Sample without extract served as blank. The $\%$ inhibition was calculated using the formula:

$$
\% \text { inhibition }=(\text { A of Control }-\mathrm{A} \text { of test } / \mathrm{A} \text { of Control }) \times 100
$$

\section{Results and Discussion:-}

\section{Extraction:-}

The Seaweed (Hypnea cervicornis) sample was extracted by means of cold extraction method using methanol. Methanol has a polarity index of 5.1 and was found to be capable of dissolving polar compounds. Therefore methanol was highly preferred and the solvent was also reported to have been used by other authors for their extraction purposes (Hafizur Rahman et al., 2014). The Percentage yield of Seaweed crude extract was found to be $3.16 \%$ and it has been reported to be the total yield for about 50 grams of the dry weight of the sample (A.Mastan et al., 2014). A Study by Anant Achary et al., 2014 has reported the extraction of Seaweed Sargassumwightii using 4 different solvents such as hexane, diethyl ether, acetone and methanol wherein the percentage yield was found to be maximum in acetone extract $(0.969 \%)$ and minimum yield was obtained in hexane extract $(0.225 \%)$.

\section{Identification of Secondary metabolites - Thin Layer Chromatography:}

Thin layer chromatography is a technique used for the separation of secondary metabolites in the seaweed extract by using the solvents in different ratios. Thin layer chromatography was used to identify the presence of Glycosides and alkaloids in the Seaweed sample. For Glycosides the mobile phase used is Toluene: methanol: glacial acetic acid: water = 7:4:3:1 and the bands were visualized by placing it in the iodine chamber while for Alkaloids the mobile phase used is Butanol: acetic acid: water $=\mathbf{4 : 1 : 3}$ and the bands were visualized by spraying it with Dragendroff's reagent (Fig 3). The solvent systems were used based on the paper by Viseshni R et al., 2017. 


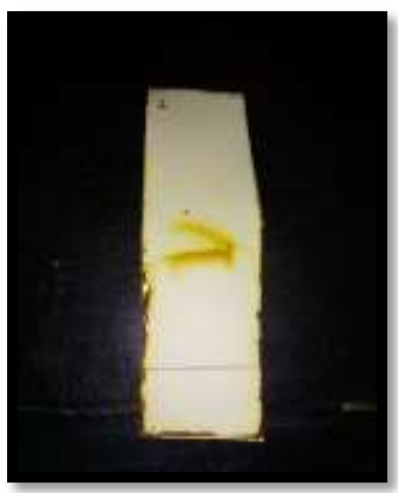

Figure 3a: TLC for Seaweed Glycoside

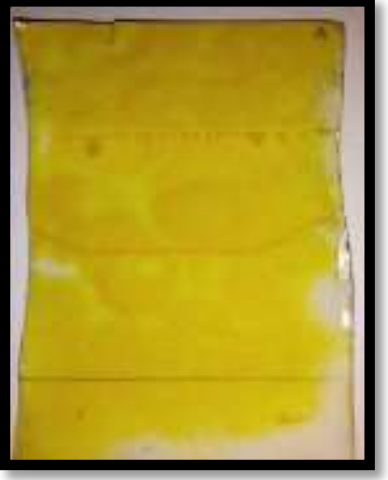

Figure 3b: TLC for Seaweed Alkaloid

Figure 3: Thin Layer chromatography for detection of Glycoside and Alkaloid compounds

\begin{tabular}{|c|c|c|}
\hline S.NO & COMPOUNDS & $\mathbf{R}_{\mathbf{f}}$ VALUES \\
\hline 1 & Glycoside & $0.375,0.125$ \\
\hline 2 & Alkaloid & $0.63,0.526$ \\
\hline
\end{tabular}

Table 1:- $\mathrm{R}_{\mathrm{f}}$ Values of the Glycoside and Alkaloid bands of Seaweed

The $R_{f}$ Values obtained for the TLC detection of glycoside compound was found to be $0.375,0.125$ (Ravindra C. Sutar et al., 2014) similarly the $\mathrm{R}_{\mathrm{f}}$ Values obtained for the TLC detection of alkaloid compound was found to be 0.63, 0.526 (Karthikeyan S et al., 2013) (Table 1).

\section{Isolation and Purification of Secondary metabolites - Column chromatography:-}

Column chromatography is performed in order to purify the individual compounds present in the sample from a mixture of compounds. The purified fractions collected by means of Column chromatography were sent for GC-MS (Gas chromatography - Mass spectrometry) analysis in order to identify the major metabolites or the compounds present in the purified sample. Stationary phase is Silica gel (100 - 200 mesh), Mobile phase for Glycosides Toluene: methanol: glacial acetic acid: water $=\mathbf{3 5 : 2 0 : 1 5 : 1 0}$ and for Alkaloids - Butanol: acetic acid: water $=$ 40:10:30
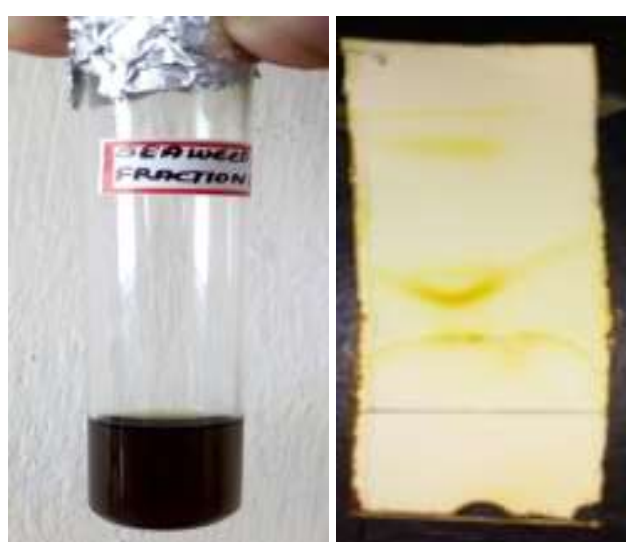

Figure 4a:-Purified Glycoside fraction I
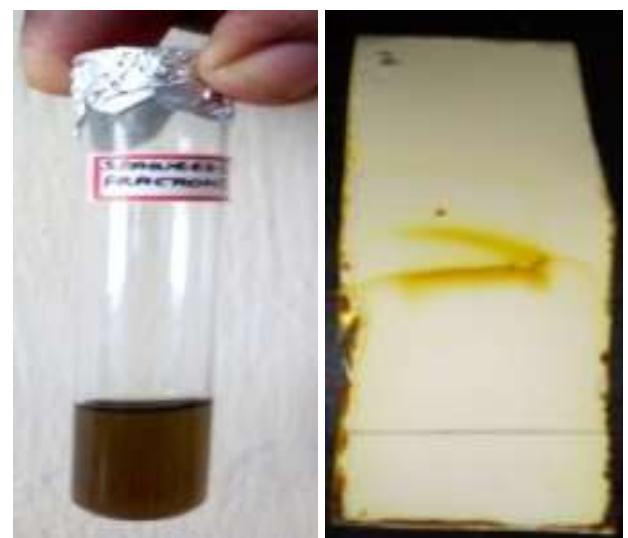

Figure 4b:-Purified Glycoside fraction II 


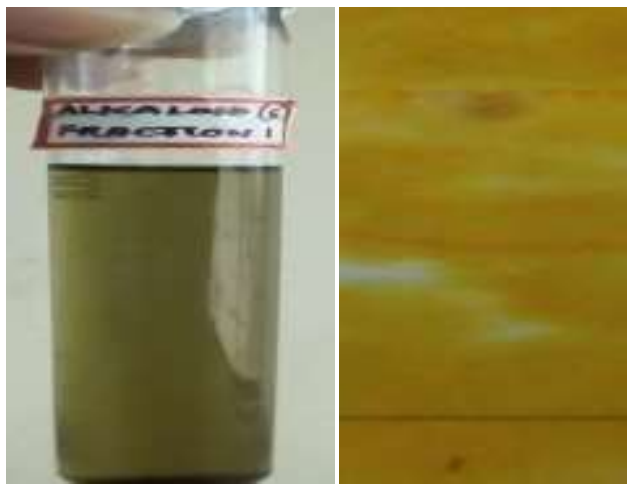

Figure 4c:-Purified Alkaloid fraction I

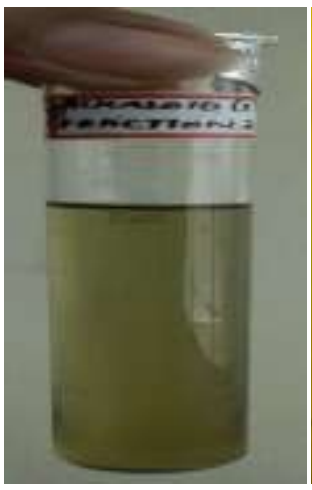

Figure 4d:-Purified Alkaloid fraction II

Figure 4: Purified Glycoside and Alkaloid fractions obtained through column chromatography

Among both the fractions the Glycoside fraction I and Alkaloid fraction 1 (Fig 4) was subjected to confirmation by performing Keller-Killani test and Dragendroff's test to detect the presence of glycoside and alkaloid compounds in that particular fraction and TLC was also carried out and the corresponding $\mathrm{R}_{\mathrm{f}}$ values were recorded.

\begin{tabular}{|c|c|c|}
\hline S.NO & COMPOUNDS & $\mathbf{R}_{\mathbf{f}}$ VALUES \\
\hline 1 & Glycoside & 0.375 \\
\hline 2 & Alkaloid & 0.630 \\
\hline
\end{tabular}

Table 2:- $\mathrm{R}_{\mathrm{f}}$ Value of the Purified Glycoside and Alkaloid fractions of Seaweed Hypnea cervicornis

The $R_{f}$ values obtained for the TLC detection of individual purified fractions were found to be 0.125 and 0.526 (Table 2). The values were compared with reference using various literatures and are considered to be glycoside and alkaloid compounds respectively (Ravindra C. Sutar et al., 2014) (Karthikeyan S et al., 2013).

\section{Confirmatory test for Glycoside and Alkaloids:-}

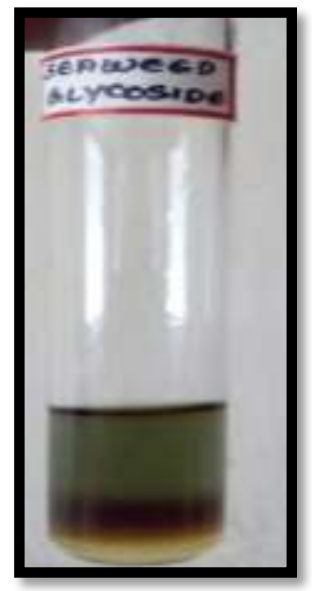

Figure 5a:- Confirmatory test for Glycoside Figure 5:- Confirmatory test performed for the purified Glycoside and Alkaloid fractions I

The appearance of Reddish brown ring at the junction of two layers indicates the presence of Glycoside and the formation of orange red coloured complex indicates the presence of Alkaloid in the Seaweed sample (Fig 5).

\section{Gas chromatography - Mass spectrometry (GC-MS):-}

The Purified fractions (Glycoside fraction I and Alkaloid fraction I) were then subjected to identification by Gas chromatography-Mass spectrometry. It is an analytical method used for identifying different compounds within a test sample. In this study Glycoside and alkaloid compounds isolated through column chromatography were identified by means of GC-MS technique. The acquisition parameters followed for GC-MS analysis: Oven: Initial 
temp $60^{\circ} \mathrm{C}$ for $2 \mathrm{~min}$, ramp $10^{\circ} \mathrm{C} / \mathrm{min}$ to $300^{\circ} \mathrm{C}$, hold $6 \mathrm{~min}$, Total Run Time: 32.00 mint InjA auto $=260^{\circ} \mathrm{C}$, Volume $=1 \mu \mathrm{L}$, Split=10:1,Flow Rate: $1 \mathrm{~mL} / \mathrm{mint}$, Carrier Gas=He, Column=Elite-5MS (30.0m, 0.25mmID, 250 $\mu \mathrm{m}$ df).

\section{Seaweed Glycoside:-}

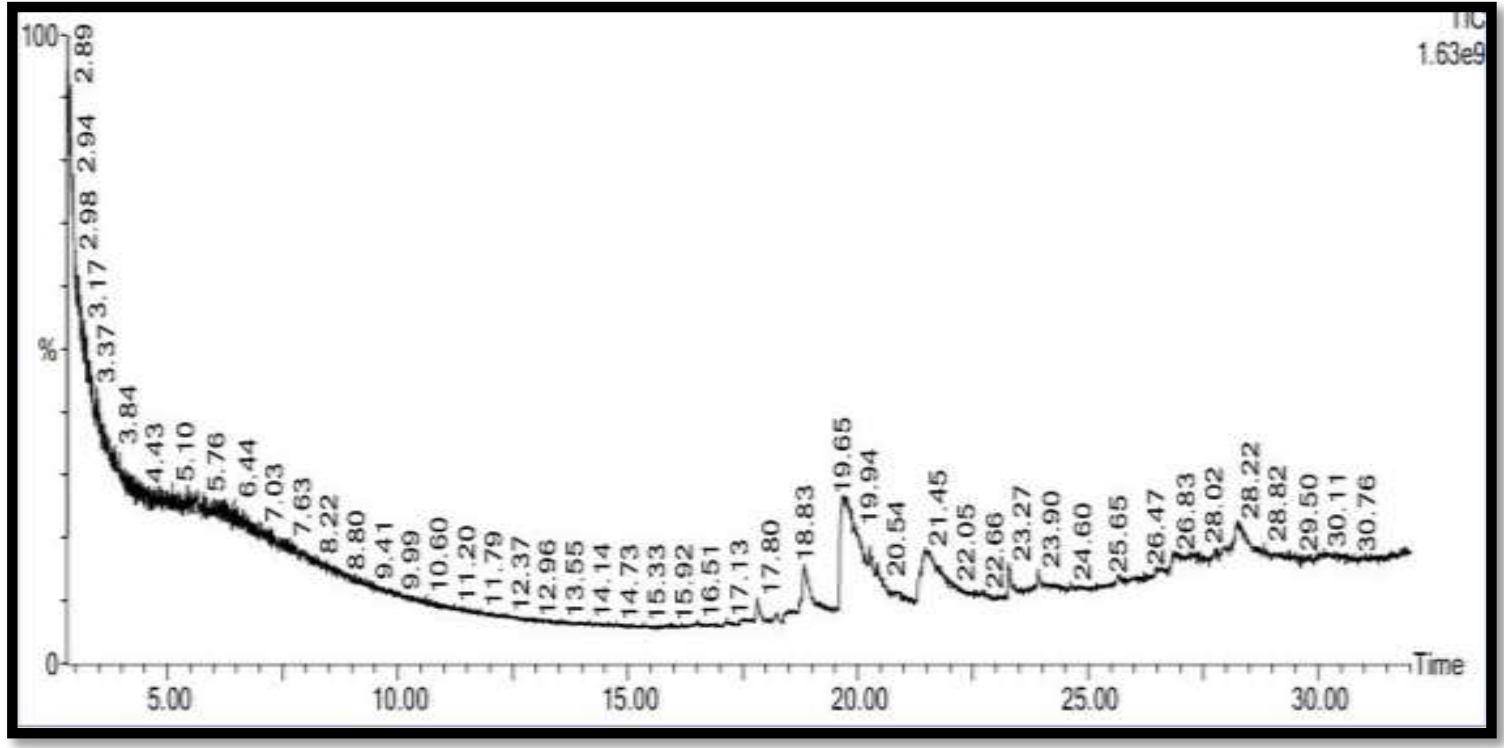

Figure 6a:-GC-MS Chromatogram of Seaweed Glycoside fraction showing various peaks at different retention time

GC-MS analysis revealed the presence of 11 different compounds in the fraction at different retention times such as Phytol (17.814), Heptacosanoic acid, methyl ester (18.830), N- Hexadecanoic acid (19.695), Oleic acid (20.255), Eicosanoic acid (20.415), 1-Tridecene (21.366), Pentadecanoic acid (21.461), Oxalic acid , monoamide, N-Allyl -, Hexadecyl ester (23.271), 6, 10- Dimethyl - 4 - Undecanol (27.963), Preganane-20-one, 3-hydroxy- (28.258), Tristearin (28.398) respectively (Fig 6a).

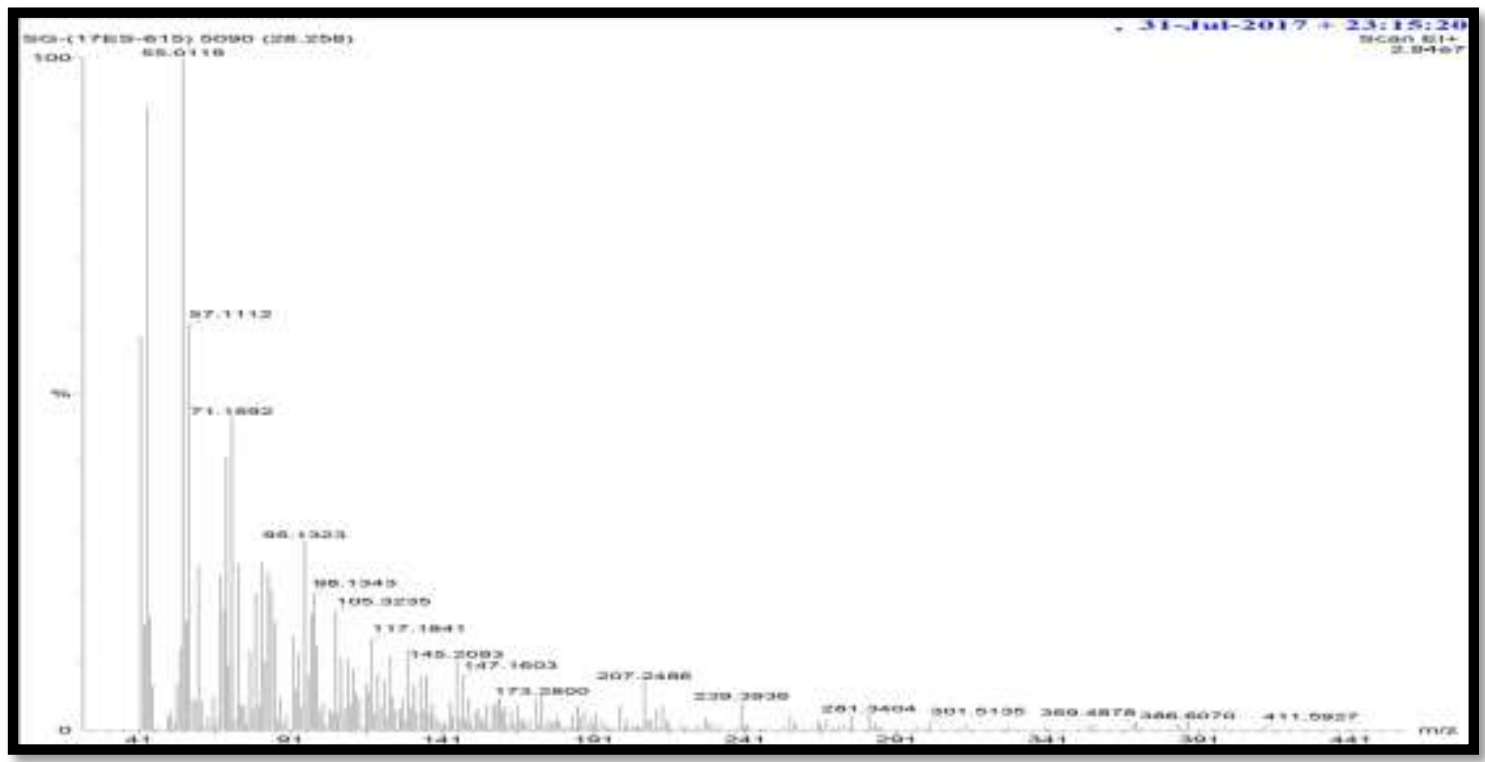

Figure 6b:- GC-MS spectrum for Seaweed Glycoside (Pregnane-20-one, 3-hydroxy-)

Among the obtained compounds Pregnane-20-one, 3-hydroxy- with retention time 28.258 was identified to be a Steroidal glycoside and the GC-MS spectrum for the corresponding glycoside is also given in the Fig $6 \mathbf{b}$. They play an important role in pharmaceutical industries where they are utilized for medicinal purposes and also in food industry in the form of food additives. They are found to be widely used in the treatment of obesity, in decreasing 
the blood glucose and blood pressure levels and also in lowering the body mass index (BMI) (Garcia VP et al., 2011).

\section{Seaweed Alkaloid:-}

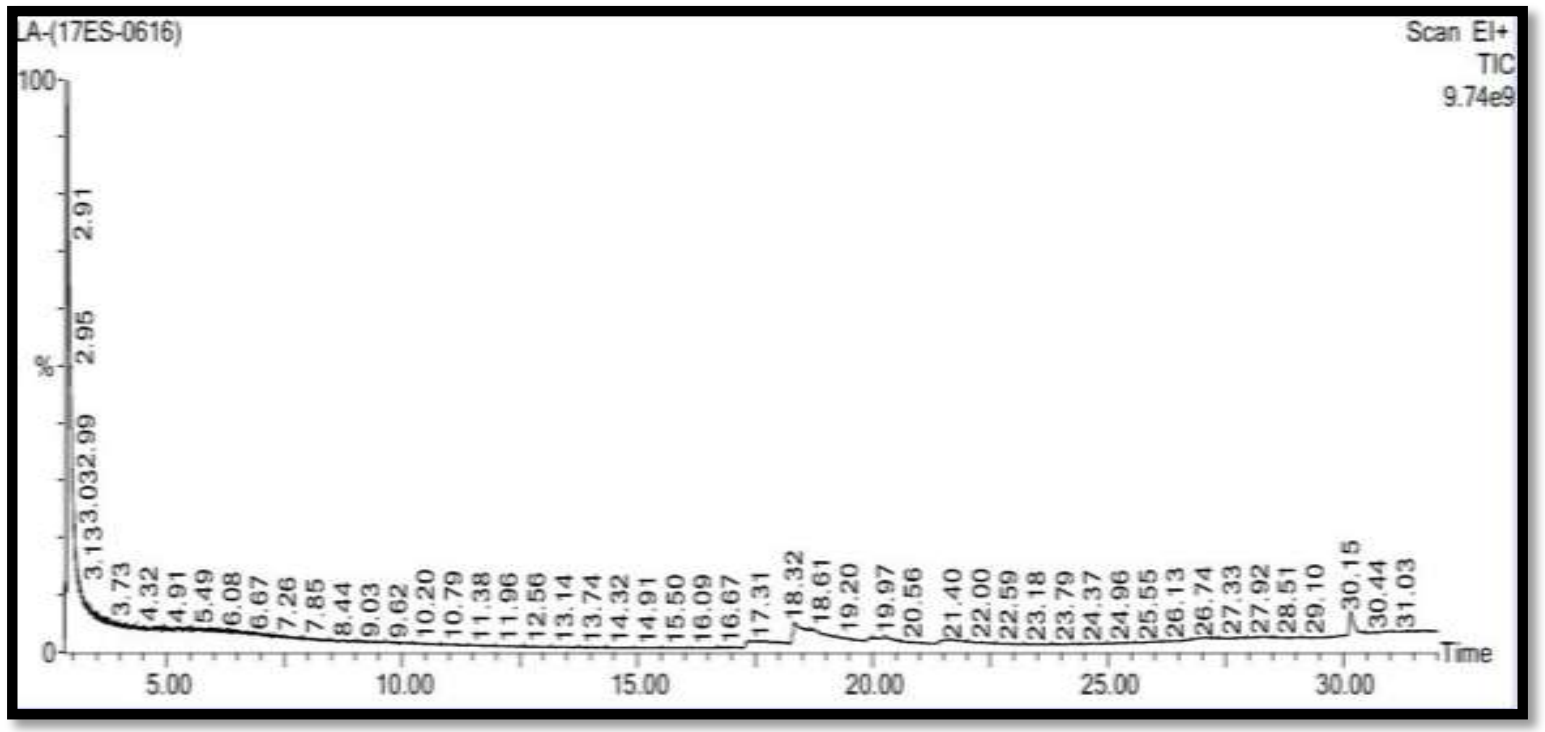

Figure 6c:- GC-MS Chromatogram of Seaweed Alkaloid fraction showing various peaks at different retention time

GC-MS analysis revealed the presence of 9 different compounds in the fraction at different retention times such as 3, 5-dihydroxytoluene (17.544), 2, 5, 9-Tetradecatriene, 3, 12-Diethyl- (18.089), Pyrrolidine, 1- (1-Cyclohexen-1-yl) (18.325), Cyclohexane carbonitrile, 1-(1-Pyrrolidinyl)- (18.710), 1-Methylheptyl trans-2, 2-Dimethyl - 3- (2methyl-1-Propenyl) cycloprop (19.935), P-Dodecyclobenzaldehyde (19.970), 7-Anti-Acetyl-3,3-Dimethylbicyclo (2.2.2) octan-2-one (20.250), P-nitrophenyl Hexadecyl ether (20.435), 3-octen-2one,3-Butyl- (30.149) (Fig 6c).

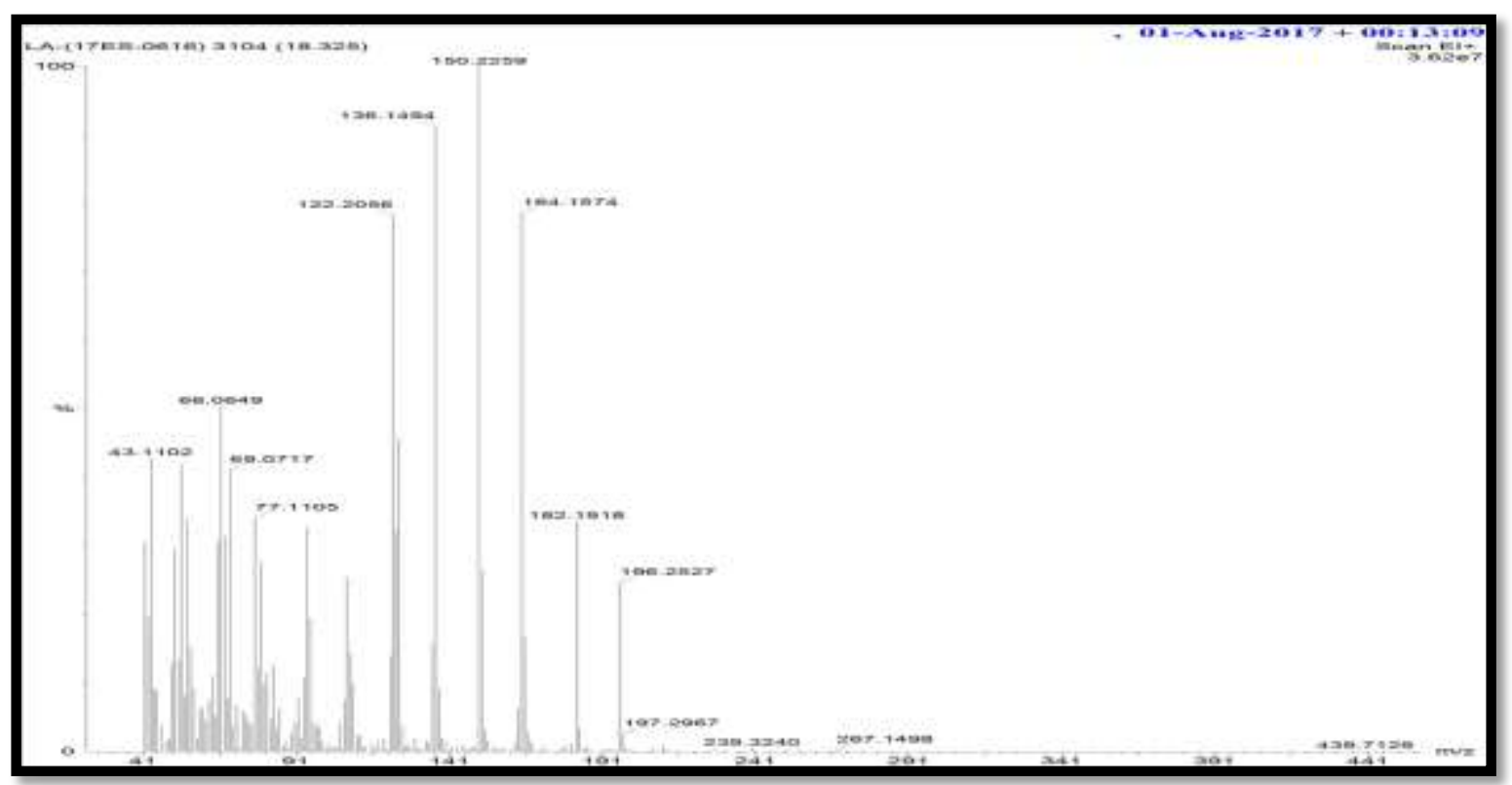

Figure 6d:- GC-MS Spectrum for Seaweed Alkaloid (Pyrrolidine, 1-(1-Cyclohexen-1-yl)-)

Figure 6: GC-MS analysis of Glycoside and Alkaloid compounds from Seaweed Hypnea cervicornis

Among the obtained compounds Pyrrolidine, 1-(1-Cyclohexen-1-yl) - with retention time at 18.325 was identified to be an alkaloid and the GC-MS spectrum for the corresponding alkaloid is also given in the Fig 6d. Pyrrolidine 
compound is found to exhibit wide therapeutic applications such as radical scavenging, Hepatoprotective, antiinflammatory, antitumor and metal chelator functions apart from this they are also found to possess antibacterial and antifungal activities. They are mainly found in many pharmaceutical drugs. Pyrrolidine is also distributed in food stuffs in trace amounts and acts as a flavouring agent (Chinmay Bhat., 2015).

The compounds identified through GC-MS analysis were then subjected to application oriented studies wherein the antimicrobial, antioxidant and antidiabetic applications of the purified Glycoside and Alkaloid fractions of Seaweed Hypnea cervicornis were assessed.

\section{Antimicrobial Activity:-}

The antibacterial activity of the Seaweed glycoside and alkaloid fractions were determined against both the Gram positive and Gram negative bacteria such as Staphylococcus aureus, Streptococcus spp, Escherichia coli, Klebsiella pneumoniae, Salmonella spp and Pseudomonas aeruginosa at different concentrations.

\begin{tabular}{|c|c|c|c|c|c|c|c|c|c|c|c|}
\hline \multirow{3}{*}{ S.NO } & \multirow{3}{*}{ ORGANISM } & \multicolumn{10}{|c|}{ ZONE OF INHIBITION (in mm) } \\
\hline & & \multicolumn{5}{|c|}{$\begin{array}{c}\text { SEAWEED GLYCOSIDE } \\
\text { Concentration }(\mathrm{mg} / \mathrm{ml})\end{array}$} & \multicolumn{5}{|c|}{$\begin{array}{l}\text { SEAWEED ALKALOID } \\
\text { Concentration }(\mathrm{mg} / \mathrm{ml})\end{array}$} \\
\hline & & 20 & 40 & 60 & 80 & $\mathbf{C}$ & 20 & 40 & 60 & 80 & $\mathbf{C}$ \\
\hline 1 & E.coli & 3 & 4 & 5 & 10 & 0 & 3 & 3 & 4 & 5 & 0 \\
\hline 2 & Streptococcus spp. & 3 & 5 & 7 & 12 & 0 & 2 & 4 & 5 & 9 & 0 \\
\hline 3 & Klebsiella Pneumoniae & 2 & 2 & 4 & 6 & 0 & 3 & 3 & 5 & 8 & 0 \\
\hline 4 & Staphylococcus aureus & 1 & 4 & 7 & 7 & 0 & 4 & 5 & 7 & 10 & 0 \\
\hline 5 & Salmonella typhimurium & 2 & 5 & 6 & 10 & 0 & 4 & 6 & 7 & 8 & 0 \\
\hline 6 & $\begin{array}{c}\text { Pseudomonas } \\
\text { aeruginosa }\end{array}$ & 0 & 1 & 2 & 5 & 0 & 2 & 5 & 6 & 7 & 0 \\
\hline
\end{tabular}

Table 3:- Antibacterial activity of Seaweed Glycoside and Alkaloid fractions at different concentrations.
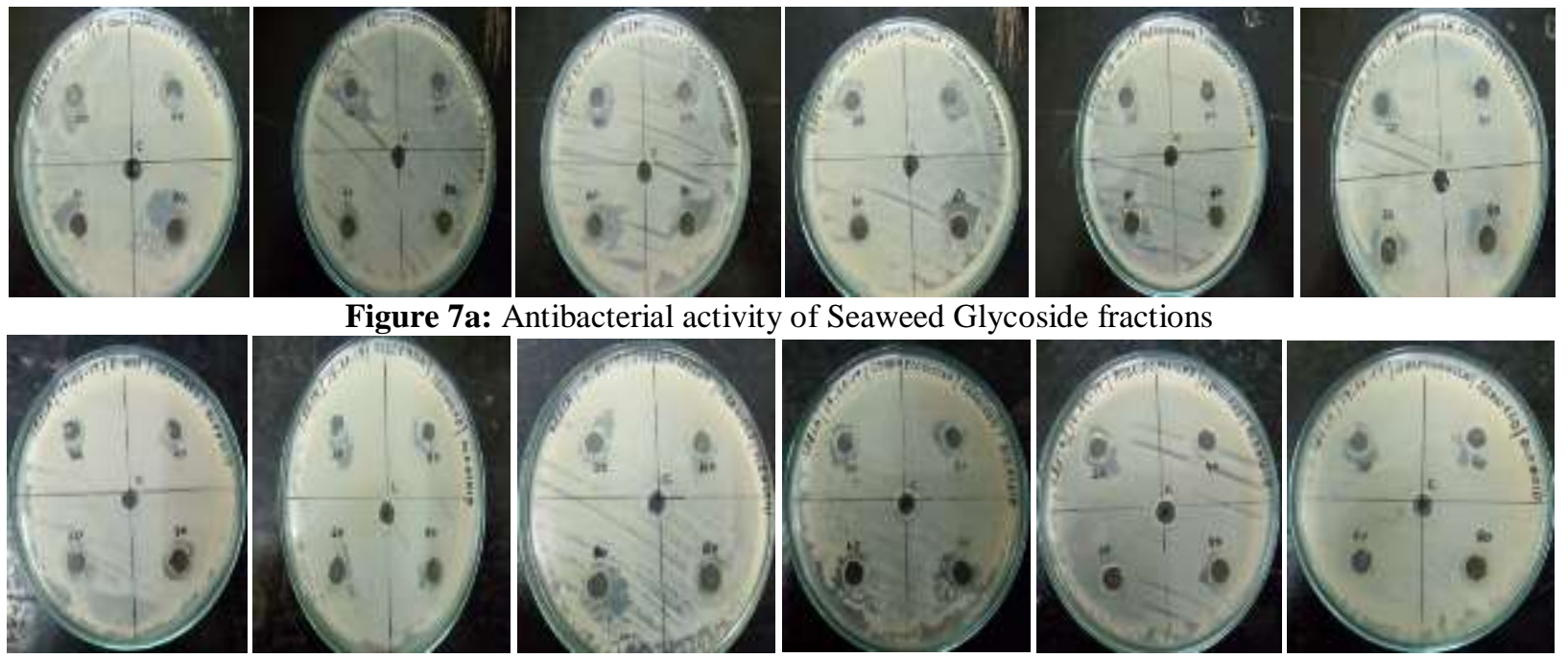

Figure 7b: Antibacterial activity of Seaweed Alkaloid fractions

Figure 7:- Antibacterial activity of Seaweed Glycoside and Alkaloid fractions at different concentrations

The antibacterial activity of the glycoside and alkaloid fractions isolated from the Seaweed Hypnea cervicornis was determined at different concentrations $(20,40,60,80 \mathrm{mg} / \mathrm{ml})$ against all the six bacterial organisms. Both the glycoside and alkaloid fractions showed good antibacterial activity at all concentrations but among them glycoside fraction was found to be comparatively better showing an increased zone of inhibition than the alkaloid (Table 3). A study by P.Vijayabaskar and V. Shylama., 2011 has reported the antibacterial activity of two brown algae Sargassumwightii and Turbinaria ornata against nine bacterial organisms in which Turbinaria ornata was found to have shown maximum inhibition against Bacillus subtilis $(20 \mathrm{~mm})$ while Sargassumwightii showed maximum inhibition against E.coli $(18 \mathrm{~mm})$ and Aeromonas hydrophila $(15 \mathrm{~mm})$ respectively. 
The antifungal activity of Seaweed glycoside and alkaloid fractions were determined against 2 fungi Aspergillus spp and Candida albicans.

\begin{tabular}{|c|c|c|c|c|c|}
\hline \multirow{2}{*}{ S.NO } & \multirow{2}{*}{ ORGANISM } & \multicolumn{4}{|c|}{ ZONE OF INHIBITION (in mm) } \\
\cline { 3 - 6 } & $\begin{array}{c}\text { SEAWEED } \\
\text { CRUDE EXTRACT }\end{array}$ & $\begin{array}{c}\text { SEAWEED } \\
\text { GLYCOSIDE }\end{array}$ & $\begin{array}{c}\text { SEAWEED } \\
\text { ALKALOID }\end{array}$ & CONTROL \\
\hline 1 & Aspergillus niger & 4 & 13 & 12 & 0 \\
\hline 2 & Candida albicans & 5 & 12 & 7 & 0 \\
\hline
\end{tabular}

Table 4:- Antifungal activity of Seaweed Crude extract, Glycoside and Alkaloid fractions.

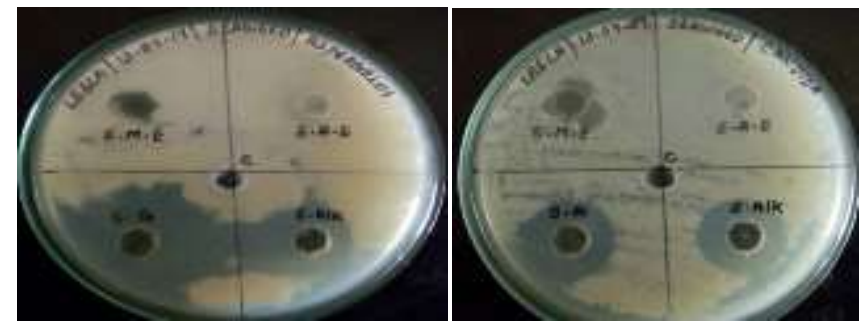

Figure 8:- Antifungal activity of Seaweed crude extract, Glycoside and Alkaloid fractions

The antifungal activity of the crude extract, glycoside and alkaloid fractions of Seaweed Hypnea cervicornis were determined against 2 fungal organisms. Both the fractions as well as the crude extract showed good zone of inhibition but comparatively glycoside fraction was found to show much better activity than the alkaloid fraction. The antifungal activity exhibited by the purified fraction was found to be even higher when compared to that of the crude extract (Table 4). A study by B. Hepsibah Elsie and M.S. Dhanarajan., 2010 has reported the antifungal activity of the methanol, ethanol and acetone extracts of Seaweed Gelidium acerosa against five fungal pathogens wherein methanol and acetone extract showed maximum inhibition against Candida albicans $(7 \mathrm{~mm})$ and Aspergillus flavus $(5 \mathrm{~mm})$ while ethanol extract showed maximum inhibition against Candida tropicalis $(7 \mathrm{~mm})$ and Aspergillus niger $(7 \mathrm{~mm})$ respectively.

\section{Antioxidant activity:-}

The antioxidant activity of the Seaweed crude extract as well as the purified fractions was carried out by means of three assays: Total antioxidant capacity assay, Hydrogen peroxide scavenging assay and reducing power assay.

Total antioxidant capacity (TAC) assay: It is an important assay used widely in order to detect the antioxidant potential of the biological samples and is carried out by means of phosphomolybdenum method. The amount of free radicals scavenged by the test solution can be measured. This technique is based on the principle of reduction of Phosphate -Mo (VI) to Phosphate - Mo (V) by the test sample and the immediate formation of bluish green coloured Phosphate/Mo complex at an acidic $\mathrm{pH}$. It possess several advantages that include its low cost, speed of reaction and the assay can also be performed using either automated or manual methods (Rohan Sharadanand Phatak and Anup Subash Hendre, 2014) 


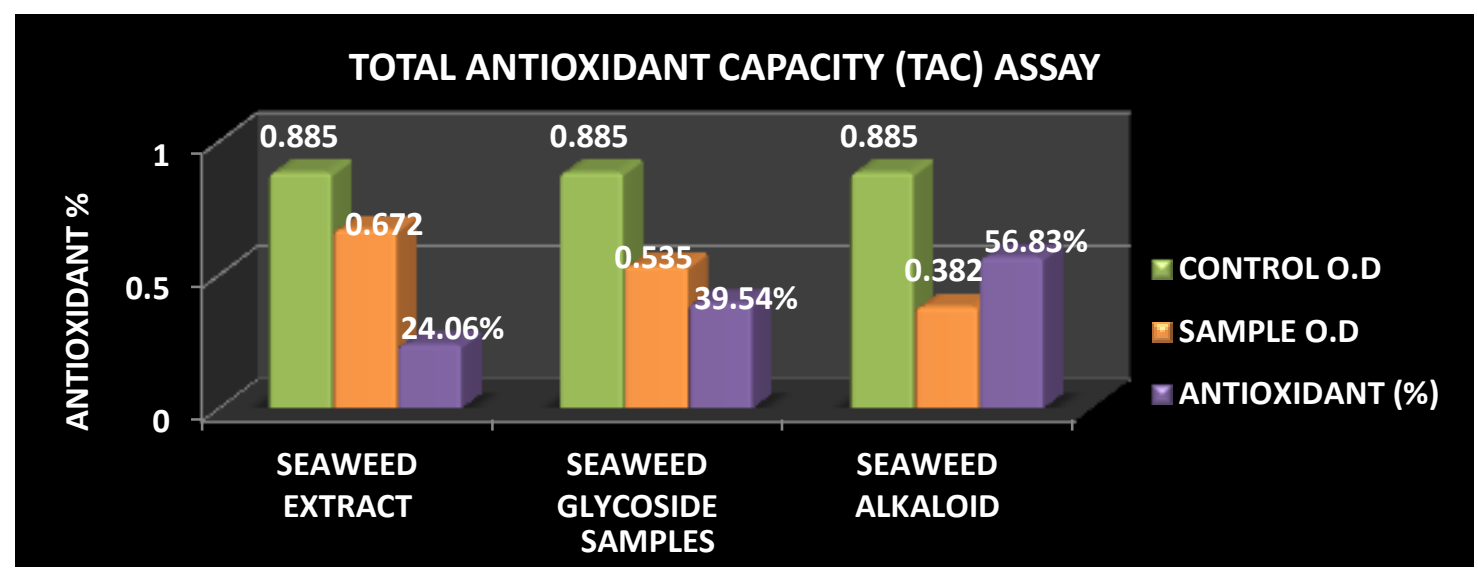

Figure 9:- Total antioxidant capacity (TAC) assay for Seaweed crude extract and purified fractions

The Total antioxidant capacity (TAC) of the Seaweed crude extract and the individual purified fractions were determined. In case of TAC assay both glycoside and alkaloid compounds showed good antioxidant percentage but on comparison alkaloid compound was found to have shown a good \% of activity (56.83\%) than the crude extract (24.06\%) and the glycoside fraction (39.54\%) respectively (Fig 9). A study by Selvaraju Meenakshi et al., 2012 has reported the total antioxidant capacity of the Seaweeds Sargassum wightii and Ulva lactuca. Among both the samples Sargassumwightii was found to have shown higher antioxidant activity compared to that of Ulva lactuca.

Hydrogen peroxide scavenging assay: Hydrogen peroxide is generally a weak oxidizing agent. Inside the cell hydrogen peroxide reacts with $\mathrm{Fe}^{2+}$ or $\mathrm{Cu}^{2+}$ ion and gets converted into hydroxyl radical which could cause toxic and harmful effects and thereby could also lead to cell damage. So it is important to prevent the formation of hydroxyl radical by preventing the accumulation of hydrogen peroxide within the cell. This assay is based on the principle of decrease in absorbance of hydrogen peroxide upon oxidation of hydrogen peroxide. The ability of the extracts to scavenge the hydrogen peroxide is determined through this assay (Priyanka B et al., 2013).

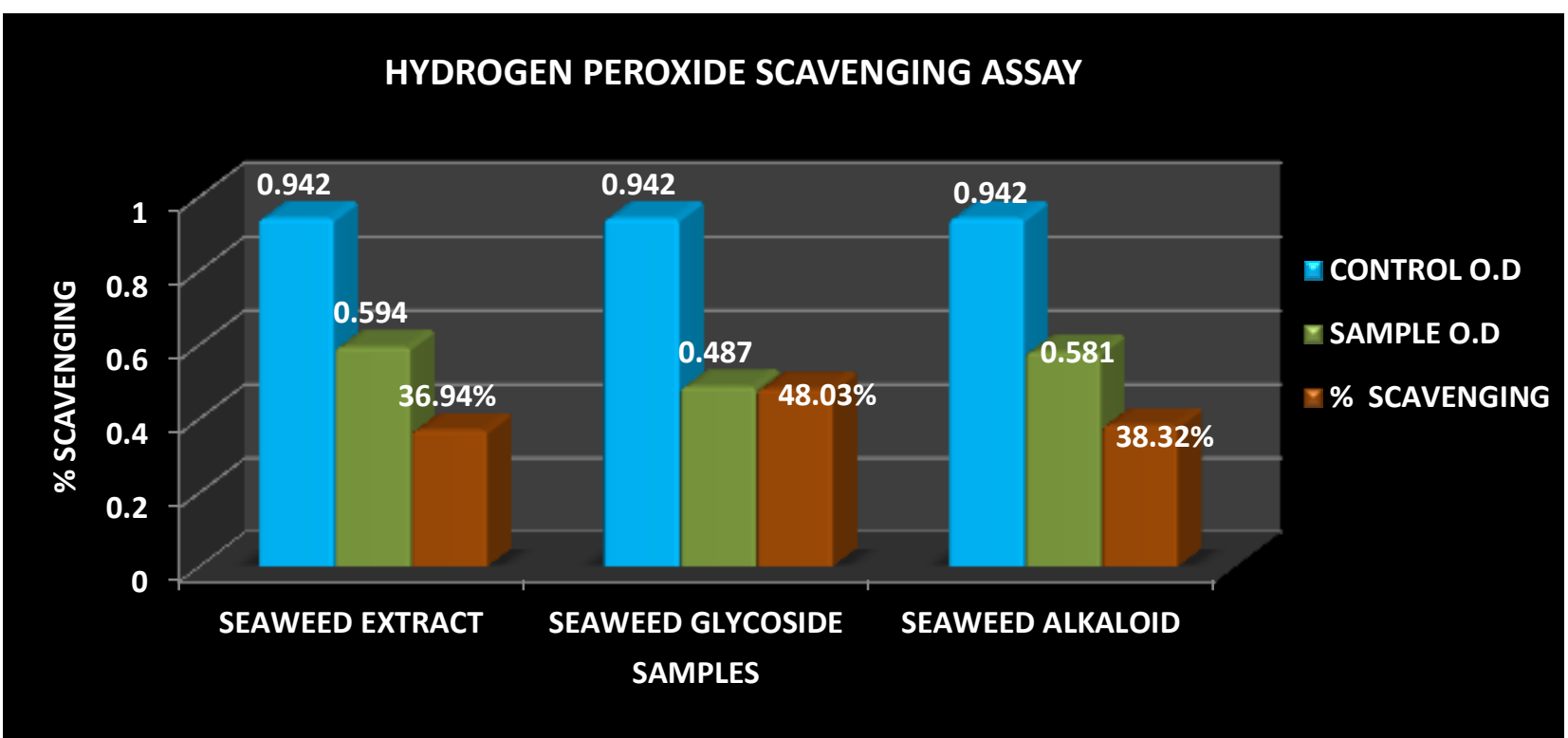

Figure 10:-Hydrogen peroxide scavenging assay for Seaweed crude extract and purified fractions

Hydrogen peroxide scavenging assay was carried out for the crude extract and the purified glycoside and alkaloid fractions of seaweed Hypnea cervicornis. Both the crude extract as well as the purified fractions showed good scavenging $\%$ but on comparing the activity of both glycoside and alkaloid compounds glycosides were found to have shown a better \% of scavenging (48.03\%) than the alkaloid fraction $(38.32 \%)$ and the crude extract $(36.94 \%)$ respectively (Fig 10). A Study by Indu.H and Seenivasan.R, 2013 has reported the hydrogen peroxide scavenging 
assay for the acetone and ethanolic extracts of 3 seaweeds such as Chaetomorpha linum, Grateloupia lithophila and Sargassumwightii at different concentrations as $0.2,0.4,0.6,0.8$ and $1 \mathrm{mg} / \mathrm{ml}$. Among the samples maximum scavenging activity was found to be observed in the ethanol extract of Grateloupia lithophila and acetone extract of Sargassumwightii while minimum activity was found in Chaetomorpha linum.

Reducing power assay:- It is a widely used technique and is based on the principle that the substances with reduction potential react with Potassium ferricyanide $\left(\mathrm{Fe}^{3+}\right)$ to form Potassium ferricyanide $\left(\mathrm{Fe}^{2+}\right)$ which again reacts with ferric chloride to form ferric-ferrous complex that has an absorption at $700 \mathrm{~nm}$. The presence of reducing compound in the extract will tend to cause the conversion of ferric form to ferrous form .By measuring the absorbance of blue colour formed at $700 \mathrm{~nm}$ it is possible to determine the concentration of $\mathrm{Fe}^{3+}$ ion .Thus the reducing ability of the crude extract and individual purified fractions were determined (P. Jayanthi and P.Lalitha.,2011).

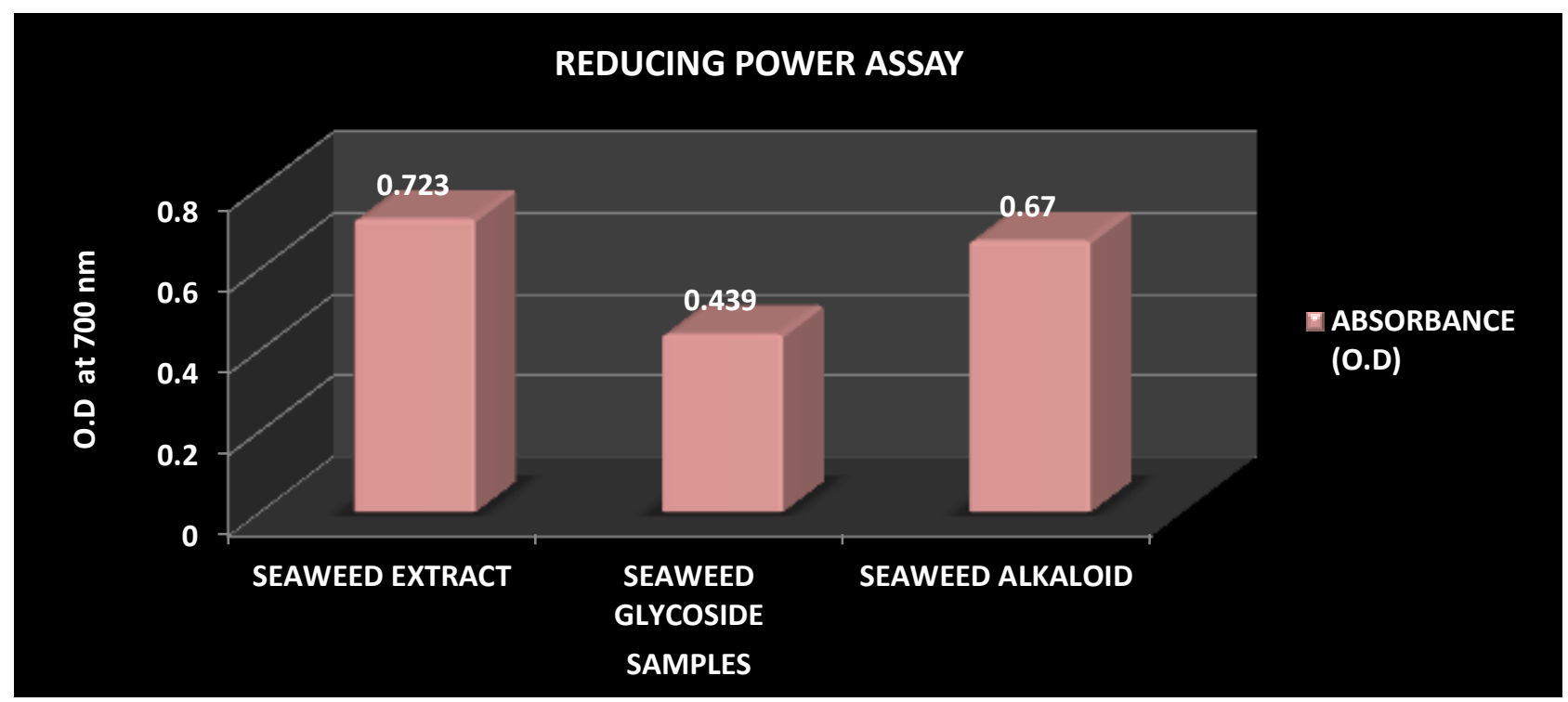

Figure 11:- Reducing power assay for Seaweed crude extract and purified fractions

Reducing power assay was carried out for the crude extract and the purified fractions of the seaweed Hypnea cervicornis. Among the samples the absorbance of alkaloid (0.67) was found to be comparatively higher than that of the glycoside fraction (0.439) but in case of reducing power assay the crude extract was found to show an increased absorbance (0.723) than that of the purified fractions but overall all the three samples showed an increased activity (Fig 11). A study by R.Rajeswari and K.Jeyaprakash, 2016 has reported the reducing power assay for the Seaweed Sargassumwightii at different concentrations such as $20,40,60$ and $80 \mu \mathrm{g} / \mathrm{ml}$ where the reducing power was found to increase with increasing concentration.

\section{Antidiabetic Activity:-}

The antidiabetic activity of the crude extract and purified glycoside and alkaloid fractions of Seaweed Hypnea cervicornis were determined by means of alpha amylase inhibition assay. It is based on the principle of in vitro breakdown of starch in the presence of $\alpha$-amylase enzyme. This process is quantified using iodine which gives blue colour on reaction with starch. The decrease in the intensity of blue colour indicates the breakdown of starch by the enzyme into monosaccharides. If the activity increases then the intensity of blue colour will be more or higher thus the intensity of blue colour developed is found to be directly proportional to the alpha amylase inhibitory activity (Sheikh et al., 2008). 


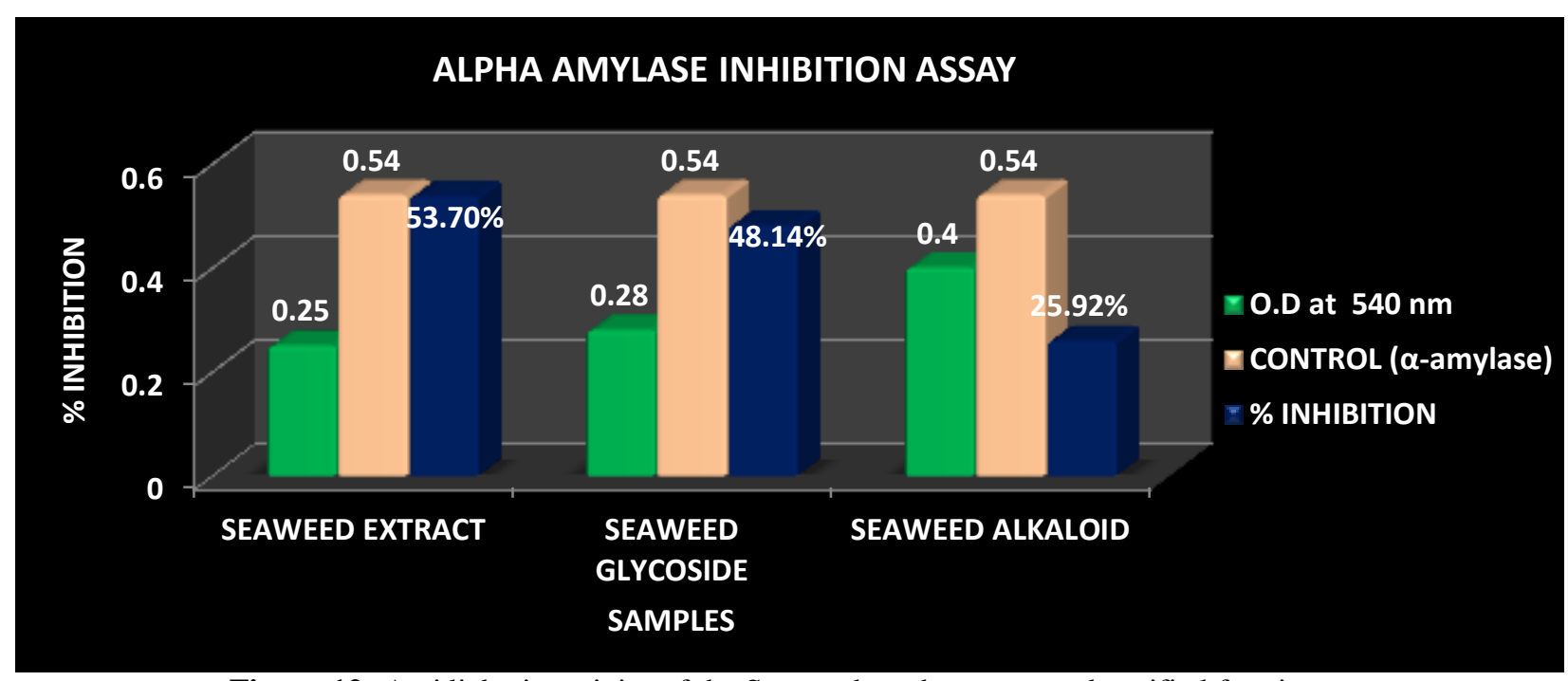

Figure 12: Antidiabetic activity of the Seaweed crude extract and purified fractions

The antidiabetic activity of the Seaweed Hypnea cervicornis was determined by means of alpha amylase inhibition assay in which the \% inhibition of the crude extracts as well as the purified fractions were determined.The crude extract from seaweed showed better inhibition \% (53.70\%) but comparatively the purified compounds also showed good inhibition $\%$ and among the two purified fractions glycoside $(48.14 \%)$ was found to possess higher antidiabetic activity than the alkaloid fraction (25.92\%) respectively (Fig 12). A study by Lucy Mohapatra et al., 2016 has reported the antidiabetic activity of Petroleum ether, ethyl acetate and methanolic extract of 4 seaweeds namely Gracilaria verrucosa, Enteromorpha compressa, Ulva fasciata and Turbinaria conoides by means of alpha amylase inhibition assay. Among all the extracts the ethyl acetate extract of Seaweed Ulva fasciata was found to have shown potent antidiabetic activity compared to that of the other extracts

\section{Conclusion:-}

The Present study was carried out in order to explore the potential of individual secondary compounds such as glycoside and alkaloid isolated from Seaweed Hypnea cervicornis in different therapeutic applications such as antimicrobial, antioxidant and antidiabetic activity. A number of seaweed compounds are being screened and extracted to test their pharmacological potential so that these compounds can also be employed in developing therapeutically important drugs. Since the compounds are derived from natural sources they do not cause any health impacts or don't pose any threat to the environment. The use of drugs derived from these natural sources could also help in treating a number of diseases due to the accumulation of bioactive compounds. Many of the compounds derived from these natural sources have been found to possess numerous pharmacological properties. Not much work has been reported before on the isolation of glycoside and alkaloid compounds from seaweed so this study was an attempt to identify the presence of such beneficial compounds in Seaweed that could prove to be useful for different applications.

\section{Acknowledgement:-}

The authors are grateful to the management of Women's Christian College, for the support.

\section{Conflict of interest:-}

The authors declare that they have no conflict of interest.

\section{References:-}

1. Mastan, A., Sreedevi, B., Pramoda Kumari., J 2014. Evaluation of the in vitro Antioxidant and Antibacterial Activities of Secondary Metabolites produced from Lichens. Asian Journal of Pharmaceutical and Clinical Research, 7(1), 193-198.

2. Abbott I.A., 1996. New species and notes on marine algae from Hawaii. Pacific science.50, 142-156.

3. Anant Achary., Karthika Muthalagu., ManojSaravana Guru., 2014. Identification of phytochemicals from Sargassumwightii against Aedesaegypti. International Journal of Pharmaceutical sciences, 29(1), 314-319. 
4. Hepsibah, B., Elsie, Dhanarajan, M.S., 2010. Evaluation of antimicrobial activity and phytochemical screening of Gelidiumacerosa. Journal of Pharmaceutical sciences and research, 2 (11), 704-707.

5. Blunt, J. W., Copp, B. R., Keyzers, R. A., Munro, M. H. G., Prinsep, M. R., 2012 .Nat. Prod. Rep.29, 144.

6. Chinmay Bhat., 2015. Synthetic studies of alkaloids containing Pyrrolidine and Piperidine structural motifs, Chemistry open, 4, 192-196.

7. Daisy, A., Indra, V., Geetha, S., Seetharaman, S., and Selvamuthu, B., 2016. Phytochemical profiling of seaweeds collected from Pulicat Lake, Coramandel coast of South India.World Journal of Pharmacy and Pharmaceutical sciences, 5(7), $1292-1297$.

8. Ferreira, I. C. F. R., Baptista, P., Vilas-Boas, M., \& Barros, L. 2007. Free-radical scavenging capacity and reducing power of wild edible mushrooms from northeast Portugal. Food Chemistry, 100, 1511-1516

9. GarciaV.P, Bermeio, J., Rubio, S., Quintana, J., Estevez F., 2011. Pregnane Steroidal glycosides and their cytostatic activites. Glycobiology, 21(5), 619-624.

10. Gurpreet kaur, Varindra Pandhair., Cheema, G.S., 2014. Extraction and characterization of steviol glycosides from Stevia rebaudianabertoni leaves. Journal of Medical plant studies, 2(5)41-45.

11. Hafizur Rahman., Vijaya, B., Soumya Ghosh., Geetika Pant., Sibi, G., 2014. In vitro studies on antioxidant, hypolipidemic and cytotoxic potential of Parmeliaperlata. American Journal of Life Sciences, 2(6-1), 7-10.

12. Indu.H, Seenivasan, R, 2013. Invitro antioxidant activity of selected Seaweeds from south east coast of India. International Journal of Pharmacy and Pharmaceutical sciences. 5(2), 474-484.

13. Nanthini Devi, K., Ajithkumar, T.T., Dhaneesh, K.V., Marudhupandi, T., and Balasubramanian, T., 2012.Evaluation of antibacterial and antioxidant properties from brown seaweed Sargassumwightii (Greville, 1848) against human bacterial pathogens.International Journal of Pharmacy and Pharmaceutical sciences, 4, 143-149.

14. Karthikeyan, S., Sivakumar, A., Anbalagan, M., Nalini, E., and Gothandam, K.M., 2013.Fingerprinting of Alkaloids, steroids and flavanoids using HPTLC of LeucasasperaL.whole plant methanolic extract. Journal of Pharmaceutical sciences and Research, 5(3), 67-71.

15. Kumar, G.S., Jayaveera, K.N., Kumar, C.K.A., Sanjay, U.P., Swamy, B.M.V. and Kumar, D.V.K. 2007.Antimicrobial effects of Indian medicinal plants against acne-inducing bacteria. Trop. J. Pharm. Res. 6, 717-723.

16. Littler, D.S., Littler, M.M., Bucher, K.E., Norris, J.N., 1989. Marine Plants of the Caribbean, a Field Guide from Florida to Brazil. Washington, DC: Smithsonian Institution Press.

17. Lucy Mohapatra., Subrat Kumar Bhattamisra., Rama Chandra Panigrahy and Sambit Kumar Parida., 2016. Evaluation of the antioxidant, Hypoglycaemic and antidiabetic activities of some selected seaweed collected from the east coast of India. Biomedical and Pharmacology Journal. 9(1), 365-375.

18. Murugaesan, S., Bhuvaneshwari, S., and Sivamurugan, V., 2016 Evaluation of in vitro antidiabetic activity of red seaweed Portieriahornemannii(Silva) and Spyridiafusidormis (Wulfen). World journal of pharmaceutical sciences.4(6), 415-419

19. Jayanthi, P., and Lalitha, P., 2011.Reducing power of the solvent extracts of Eichhorniacrassipes (Mart.) Solms. International Journal of Pharmacy and Pharmaceutical sciences, 3, 126-128.

20. Vijayabaskar, P., and Shiyamala, V., 2011.Antibacterial activities of Brown marine algae Sargassumwightii and Turbinariaornata from the Gulf of Mannar Biosphere reserve. Advances in Biological Research. 5(2), 99-102.

21. Prieto, P., Pineda, M., Anguilar, M., 1999. Spectrophotometric quantitation of antioxidant capacity through the formation of a Phosphomolybdenum Complex: Specific application to the determination of Vitamin E. Anal. Biochem, 269, 337-341.

22. Priyanka, B., Anitha, K., Shirisha, K., Janipasha, S.K., Dipankar, B., Rajesh, K., 2013.Evaluation of antioxidant activity of ethanolic root extract of AlbiziaLebbeck (L.) Benth .International Journal of Pharmaceutical and Applied sciences. 3(2), 93-101.

23. Rajeswari, R., and Jeyaprakash, K., 2016. Phytochemical characterization and Invitro antioxidant efficacy of Sargassumwightii. World Journal of Pharmaceutical Research, 5(8)1182-1192.

24. Rajasekar Thirunavukkarasu., Priyadharshini Pandiyan., Kumaran Subramaniyan., Deivasigamani Balaraman., SakthivelManikkam., BalamuruganSadaiyappan., George Edward GnanJothi., 2014. Screening of marine seaweeds for bioactive compound against fish pathogenic bacteria and active fraction analyzed by gas chromatography-mass spectrometry. Journal of Coastal life medicine, 2(5), 367-375.

25. Ravindra C.Sutar., Sanjay B. Kasture and Kalaichelvan, V.K., 2014. Phytochemical studies on the glycosides of leaf extracts of medicinally important plant Holopteraintegrifolia (RoxB) planch using High performance thin layer chromatography. Asian Journal of Pharmaceutical and Clinical research, 7(4), 197-200. 
26. Rohan Sharadanand Phatak., Anup Subhash Hendre., 2014.Total antioxidant capacity of fresh leaves of Kalanchoepinnata. Journal of Pharmacognosy and Phytochemistry. 2(5), 32-35.

27. Ruch, R.J., Cheng, S.J., and Klaunig, J.E., 1989 Prevention of cytotoxicity and inhibition of intracellular communication by antioxidant catechins isolated from Chinese green tea. Carcinogenesis, 10, 1003-1008.

28. Sara Marsham, Graham W. Scott, and Michelle L. Tobin., 2007. Comparison of nutritive chemistry in a range of temperate seaweeds. Food Chemistry, 100, 1331-1336.

29. SelvarajuMeenakshi, ShanmugamUmayaparvathi, MuthuvelArumugam, ThangavelBalasubramanian. 2012. Invitro antioxidant properties and FTIR analysis of two seaweeds of Gulf of Mannar. Asian Journal of Tropical Biomedicine. 66-70.

30. Sheikh, J.H., Iyo, Tsujiyama, M.T., Md.Ashabul I., Rajat, S.B., Hitoshi,A.2008 .Total phenolic content, antioxidative, anti-amylase, antiglucosidase and antihistamine release activities of Bangladeshi fruits. Food Science and Technology Research.14, 261-268.

31. Sibi, G., Apsara, V., Dhananjaya, K., Ravikumar, K.R., and Mallesha. H., 2013. Phytochemical and Antibacterial properties of spices against food borne bacteria with special reference to ParmeliaperlataG.J.B.B. 2(2), 145-149.

32. Viseshni. R and PriyaR.Iyer, 2017.Screening of Antidiabetic and Anticancer activity in Andrographispaniculata (Nilavembu).World Journal of Pharmacy and Pharmaceutical sciences. 6 (8), 1837-1849. 